AperTO - Archivio Istituzionale Open Access dell'Università di Torino

\title{
Use of Thermography Techniques in Equines: Principles and Applications
}

\section{This is the author's manuscript}

Original Citation:

\section{Availability:}

This version is available http://hdl.handle.net/2318/1675783

since 2018-09-04T14:48:49Z

Published version:

DOI:10.1016/j.jevs.2013.07.007

Terms of use:

Open Access

Anyone can freely access the full text of works made available as "Open Access". Works made available under a Creative Commons license can be used according to the terms and conditions of said license. Use of all other works requires consent of the right holder (author or publisher) if not exempted from copyright protection by the applicable law. 
Review Article

\title{
Use of Thermography Techniques in Equines: Principles and Applications
}

\author{
Veronica Redaelli PhD ${ }^{\mathrm{a}}$, Domenico Bergero DVM, Dipl. ECVCN ${ }^{\mathrm{b}}$, Enrica Zucca DVM, PhD ${ }^{\mathrm{a}}$, \\ Francesco Ferrucci DVM, $\mathrm{PhD}^{\mathrm{a}}$, Leonardo Nanni Costa DAS, $\mathrm{PhD}^{\mathrm{c}}$, Lorenzo Crosta $\mathrm{PhD}^{\mathrm{d}}$, \\ Fabio Luzi DAS ${ }^{\mathrm{a}, *}$
}

${ }^{a}$ Dipartimento di Scienze Veterinarie per la Salute, la Produzione Animale e la Sicurezza Alimentare, Milano, Italy

${ }^{\mathrm{b}}$ Dipartimento di Produzioni Animali Epidemiologia ed Ecologia, Grugliasco, Italy

${ }^{\mathrm{c}}$ Dipartimento di Scienze e Tecnologie Agroalimentari, Bologna, Italy

${ }^{\mathrm{d}}$ Clinica Veterinaria Valcurone, Missaglia, Italy

\section{A R T I C L E I N F O}

\section{Article history:}

Received 30 December 2012

Received in revised form 16 June 2013

Accepted 24 July 2013

Available online 11 October 2013

\section{Keywords:}

Horse

Thermography

Infrared applications

Noninvasive diagnosis

\begin{abstract}
A B S T R A C T
This review of the use of thermographic technique in equines introduces the principles upon which infrared radiation and thermoregulatory physiology are based and describes the instrumentation used and its practical use. The advantage of this imaging technique is that it is a noninvasive thermographic examination, both from an operational (the animal and the operator) and health (no penetrating radiation is used) standpoint. Advantages and disadvantages of this technique, equine applications, and physiological assessments are discussed.
\end{abstract}

(c) 2014 Elsevier Inc. All rights reserved.

\section{Introduction}

Thermography can detect and measure infrared radiation emitted spontaneously from any object that is at a temperature above absolute zero $\left(-273.16^{\circ} \mathrm{C}\right)$ [1].

The term "thermal imaging" refers to the graphic representation of the electromagnetic radiation emitted by a surface, which is then turned into a visible image (Fig. 1).

The thermal energy, or infrared radiation, consists of electromagnetic waves whose length is too large to be detected by the human eye. It is, in fact, that portion of the electromagnetic spectrum that is normally perceived as heat. In the world of infrared energy, all items with a temperature above absolute zero emit heat; even objects that have a very low temperature, such as ice cubes, emit infrared radiation. The higher the temperature of the object the smaller the wavelength infrared radiation $[2,3]$.

\footnotetext{
* Corresponding author at: Dr. Fabio Luzi, DAS, via G. Celoria, 10, Milano, Italy.

E-mail address: fabio.luzi@unimi.it (F. Luzi).
}

The present review discusses the main applications of infrared thermography in equines [4].

\section{Principles}

Heat is generated continuously by the body and is dissipated through the surface in several ways: by radiation, convection, conduction, and evaporation. In fact, the surface temperature is generally a few degrees lower than body temperature.

The superficial heating is influenced by local circulation and tissue metabolism that is generally constant. Clearly, areas with higher metabolism have a higher temperature than areas with less tissue activity. The surface temperature changes are caused by changes in local perfusion. Usually the veins are hotter than arteries, because draining the flow from areas metabolically active and the venous drainage from tissues or organs with a high metabolic rate have a temperature higher than the venous drainage from areas with a normal metabolism. The vascularity and its blood supply are the bases of representation thermography; the 


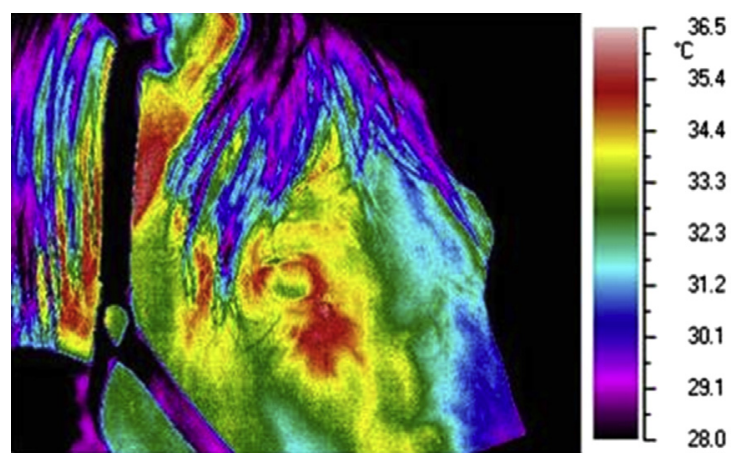

Fig. 1. Thermographic image of the head of a horse.

skin overlying muscles is subject to an increase in temperature during muscular activity, and the pattern of physiological thermographic area can be predicted according to the structure of his system bloodstream.

Heat is also one of the main signs of inflammation, as increased blood supply caused by inflammation leads to an increase in temperature. Trauma or tissue lesions always cause a change in the circulation, and thermography can detect a "hot spot" that is associated with local inflammation, or injury in the repertoire can be a decrease in temperature caused by venous thrombosis, a reactive edema, a phenomena that shunts to divert blood flow, infarction or damaged organ that behaves like the storage of blood without flow and then loses heat and is detected as a point of lower temperature.

These lesions appear on the thermogram as heat losses and are often surrounded by a alone of temperature increases because of diversion of flow from the damaged area to the adjacent areas. For the blood supply in a given area, several considerations can be made, according to the thermogram. Therefore, valuable information will be provided so that the clinician can figure out a diagnosis or at least make a physiological assessment (Fig. 1) [2,3,5,6].

\section{Instrumentation}

Imaging techniques are divided into two categories: anatomical and physiological techniques. Thermography belongs to the latter group because it is able to detect metabolic activity, thus providing a dynamic, real-time image of the object under examination. Thermal images are obtained with infrared cameras.

The first instruments used specialized liquid crystals that change size in contact with a heat source. Because their ability to reflect light is affected by their structure, we can evaluate the temperature according to the color that is reflected by the different crystals. Currently, new cameras are used with uncooled sensors and are portable, thereby achieving significant practical advantages.

An infrared detector with a series of fires and scanner measures the intensity of infrared radiation; this signal is then converted into electrical form by a cathode which produces a gray scale image of the object under examination. The intensity of infrared radiation is converted into gray level, and then, through the use of special software, the thermographic image is processed and produced in a false color scale $[2,3,5]$.

\section{Practical Use}

To obtain reliable images, factors such as movement of the subject matter, any extraneous radiation in the environment, ambient temperature, and artifacts need to be checked. For example, movement can be controlled by physical constrains, but containment by drug should not be used so that false thermographic patterns caused by the sedative principle on the peripheral circulation are avoided.

To reduce the effects of radiant sources from other objects, the thermographic examination should be performed in areas sheltered from the sun; furthermore, thermographic pictures should be taken in the absence of airflow, as it might increase heat loss. It is also important for the subject to take $15-20 \mathrm{~min}$ to acclimate to the environment where thermography will take place.

Artifacts can be produced by any material on the body surface, such as dirt, thick hair, scars, and bands. Finally, it is advised that more than one thermographic image be obtained from different sides and different angles.

\section{Advantages and Limitations}

Thermography is defined as a noninvasive imaging method, because it does not imply any surgical access to the body of the patient; furthermore, it cannot cause any damage to either the patient or the operator. Thermographic examination does not use any penetrating radiation, as in radiography or computed tomography, and the anatomical part that is examined does not receive ultrasound waves, like in ultrasonography, and is not placed in an electromagnetic field as in magnetic resonance imaging; finally, thermography does not use any radioactive substances, as in scintigraphy. Given this, thermography is certainly the least invasive for both the patient and the operator among all diagnostic imaging techniques.

Thermography can be considered a physiological method, because it provides a real-time evaluation of changes over time, creating a dynamic image of the object: this characteristic represents a considerable advantage over other imaging techniques that offer only static representations, such as radiography, tomography, and magnetic resonance imaging. It can detect surface temperature in a much more objective and sensitive way than clinical palpation. Thermography appears to be a highly sensitive technique as it detects the radiation emitted by the object, turning it into a temperature rating, and for the physical laws on emission of heat, even for small changes in temperature, there are large variations in energy.

Another key advantage of this technique is its ability to be used as a preventive method in the sense that it can highlight variations that do not yet lead to clinical signs. Detection of temperature changes in a clinically healthy subject is a helpful tool to estimate the possible development of future disease and can give early warning signals, allowing the health provider to make decisions about the animal's sports program or management. It is also a useful 
method to monitor the response to therapy without interfering with the treatment.

Thermography has some limitations, as well: first, good quality thermocameras can be very expensive, and maintenance of the camera can be expensive, too; second, even if thermography can locate the pathological area and is able to provide information about the physiological and pathophysiological status, allowing considerable diagnostic support, still the technique cannot replace other diagnostic procedures; furthermore, it is unable to provide information about the origin or cause of the disease. In this perspective, thermography alone is not helpful in the formulation of an appropriate therapy [3,7].

\section{Examples of Applications in Equines}

There are at least three ways in which thermography can be used in equine veterinary practice.

The first is the use of thermography as a tool to improve the physiological assessment of the horse. Thermocameras are more sensitive than the hands of the veterinarian in detecting temperature differences; thermography can help identify the presence of asymmetries and can spot changes in temperature and point out "suspect anatomical areas." However, the veterinarian must then interpret the information obtained with thermography to investigate the cause of the temperature variation $[1,8,9]$. The second way is the use of thermography as a diagnostic tool.

In this case, the technique is used as a diagnostic imaging tool, where both increases and decreases in temperature have their significance. The thermogram identifies an area of interest where other diagnostic techniques, like ultrasonography or radiography, can be used to complete the analytical framework [10] (Fig. 2).

The third method of using this technique is in the evaluation program of animal welfare, because variation in skin temperature caused by peripheral vasoconstriction is dependent on the physiological and emotional state of the animal [11-13].

Further uses of thermography include monitoring of other clinical procedures, such as the use of certain drugs, shock therapy, and evaluation of fracture casting; finally, thermography can also be used in antidoping programs [14,15] (Fig. 2).

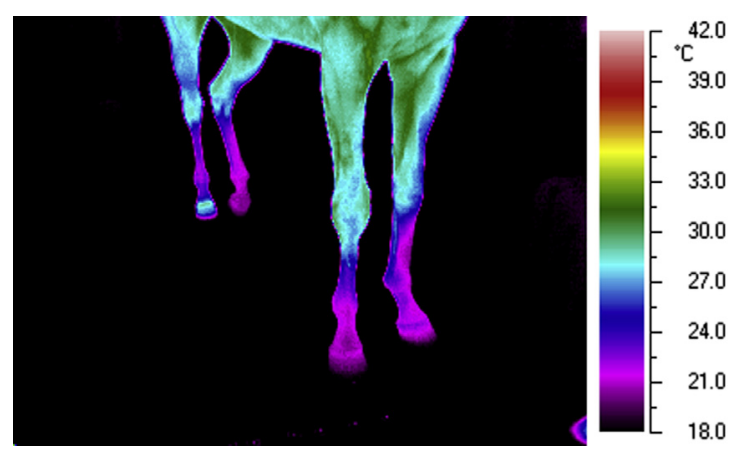

Fig. 2. Thermographic image of the limbs of a horse.

\section{Physiological Assessments}

The mechanical activity of striated muscle includes isotonic contraction and isometric tension; voluntary muscle movements that occur under physiological conditions in a body can take any intermediate characteristics between these two conditions: the antigravity muscles that keep the posture develop mainly isometric contractions, whereas the muscle movements for locomotion are contracting under isotonic conditions.

Several chemical reactions take place in the muscle, most of which are exothermic (or exoergic), and by definition, produce heat that is dissipated outside: only $25 \%$ of energy used by muscle is converted into mechanical movement, the remaining $75 \%$ of energy is dissipated as heat.

At rest, the basal metabolic activity produces a steady share of heat, the so-called basal heat; when the muscle becomes active, its heat output increases in proportion to mechanical work, and even more if the contraction is accompanied by shortening of the muscle (i.e., isotonic conditions). The measure of heat produced by muscle may therefore provide an assessment of chemical phenomena at the basis of mechanics.

The heat produced during a single contraction is called "heat activation," whereas in a state of isometric tension, the instant production of heat is constant and total production increases linearly; this is called "heat retention" and is believed to be the amount of heat of activation of individual contractions. Its increase is a function of time and effort of muscle contraction.

The "heat of relaxation" is degraded into heat energy when the stimulus of mechanical activity ceases and the muscle is released. Not to be confused with the "heat of maintenance" following the return to the resetting state of the muscle, this heat is the result of processes that bring the muscle to its starting conditions: ion pumps, ATP regeneration, and restoration of concentration gradients of various substrates.

Exercise is accompanied by a massive heat production, almost $75 \%$ of energy used by the locomotor apparatus is dissipated as heat. The horse maintains its body temperature within the physiological range $\left(37^{\circ} \mathrm{C}-40^{\circ} \mathrm{C}\right)$ by using thermoregulatory mechanisms that include thermoregulatory heat dissipation through convection as a mean of using the air surrounding the body and evaporation of sweat that is exploiting the ability to lower the surface temperature. Thermoregulation plays a key role during exercise, where the heat production increases in proportion to the intensity of physical effort.

A 2006 study [16] showed how exercise affects the surface temperatures of thoracic and pelvic limbs in horses.

They used 6 horses ( 4 geldings and 2 females) between the ages of 7 and 12 years old and weighing between 463 and $542 \mathrm{~kg}$. These subjects showed no clinical signs of lameness or injury to the skeletal muscles and were trained working on the treadmill. The procedure of the study provided for obtaining a thermographic scan 3 days before the trial to get a basal image. The work was performed on the treadmill at three speeds according to the following protocol: 5 min per step; 5 min to "small trot," that is at 
$3 \mathrm{~m} / \mathrm{sec}$; $5 \mathrm{~min}$ trotting at $6 \mathrm{~m} / \mathrm{sec} ; 5 \mathrm{~min}$ at a gallop $(8 \mathrm{~m} /$ $\mathrm{sec}$ ); then climbing for $3 \mathrm{~min}$ at a trot, $3 \mathrm{~min}$ to "small trot," and 3 min per step. The training program was carried out twice a week, and each horse was tested in six trials.

The thermal images were recorded before the beginning of the session. A scan was performed just after the training protocol and then at 5, 15, 45, and 60 min and 6 hours after completion of the training. The anatomical regions that were scanned with the thermocamera were the shoulder, the chest, the arm, the lumbar region, the buttocks, the leg, and the metacarpal and metatarsal regions.

All horses showed symmetrical bilateral variations during the scan, based on inspection carried out before the beginning of training [17].

The temperature of the muscle regions of all the horses at 5 and 15 min after the end of the training was particularly high, as were the metacarpal and metatarsal regions of all the horses in the study. The muscles increased their temperature by $6^{\circ} \mathrm{C}$ at time zero (training just completed), whereas the metacarpal and metatarsal regions showed an increase of $8^{\circ} \mathrm{C}$ at time zero, and even 45 min after the trial, they remained slightly warmer than the basal temperature. Scans run 45 min after the end of the exercise did not show any major temperature differences compared to the first image (time zero). Sixty minutes after the end of the exercise, there were no differences with the scanning control in any region.

This study shows that in all the anatomical regions there are significant temperature difference during the first 15 min after the exercise, whereas as early as 45 min after the exercise, there are no differences with scans run before the exercise start. It also shows that the area that includes the dorsal muscles returns more quickly to the basal temperature than the metacarpal and metatarsal regions; this is probably due to the greater surface through which the heat dissipation occurs.

The results of this study are important for the clinical practice of thermography, because it shows that thermographic scanning performed $45 \mathrm{~min}$ after exercise is not influenced by the mechanism of thermoregulation and thus can provide data without any risk of false positives.

\section{Training in Hot Climates}

The temperature control system acts through the autonomic nervous system, and the heart and the hypothalamus coordinate the response to increasing temperature during exercise. The heat produced by muscle activity is distributed throughout the body via the blood supply to the muscle and by venous circulation reaches the heart. The first mechanism that responds to the temperature increase is a higher cardiac output flow that is directed to the cutaneous circulation, so the blood can give up heat by convection through the skin surface.

There are certain conditions under which the temperature control system fails to balance the heat loss with the heat produced from a muscle. Thermography has shown that hyperthermia can occur when the horse is subjected to a training level that is too intense compared to its physical condition, or when the animal is not in physical condition to bear physical activity (e.g., in a state of severe dehydration) or when the training is done in an environment that is particularly wet and hot.

Under the latter condition, the cardiovascular response is no longer sufficient to balance the heat loss through the skin surface, and the muscles continue to produce heat which is spread throughout the body via the bloodstream and is directed toward subcutaneous capillary beds in an attempt to disperse the heat and then reduce the temperature, but the process of convection is slowed down when the air flow over the skin has a temperature that is too high $\left(32^{\circ} \mathrm{C}-34^{\circ} \mathrm{C}\right)$ and then the heat builds up. The gradient convection between environment and skin surface may reach levels that are reversed, that is, the skin temperature is lower than that of the environment, and in this case, the body takes heat from the outside thus increasing further hyperthermia.

Another method of heat loss is evaporation. During exercise, the temperature control system through the autonomic nervous system comes to the sweat glands that produce sweat to help heat dissipation. The skin surface in contact with sweat releases heat to sweat itself, which releases heat by evaporation to the surrounding air. The percentage of relative humidity in the environment is fundamental for this system of temperature control to function through evaporation. It has been shown that a high relative humidity ( $\mathrm{RH}=80 \%-85 \%)$ reduces the evaporation of sweat to a level where it dissipated only $5 \%$ of the heat through evaporation.

The second part of the study showed how a training program developed in a time of 2 or 3 months may induce a series of physiological adaptations to which the subject acquires the ability to thermoregulate in a hot and humid climate. These adjustments include an expansion of plasma volume by $10 \%-25 \%$ in the first week, allowing the horse to reduce its heart rate while maintaining a constant rate. Another adaptive mechanism is the increase of sweat.

Thermography is useful both to evaluate the heat loss during exercise and to check the limit of hyperthermia under particular training conditions [18].

\section{Postexercise Cooling}

In a 1998 study [19], thermography was used to assess changes in surface temperature after the application of cold water $\left(6^{\circ} \mathrm{C}\right)$ on individuals who had sustained a workout in a hot and humid climate $\left(30^{\circ} \mathrm{C}, \mathrm{RH}=84 \%\right)$.

The exercise protocol included $10 \mathrm{~min}$ at a step of $1.7 \mathrm{~m} /$ $\mathrm{sec}, 3 \mathrm{~min}$ trotting at $3.7 \mathrm{~m} / \mathrm{sec}, 4 \mathrm{~min}$ at a gallop to $8 \mathrm{~m} / \mathrm{sec}$, and $4 \mathrm{~min}$ galloping at $10 \mathrm{~m} / \mathrm{sec}$ on the treadmill inclined at $5^{\circ}$ angle without the use of the fan in order to avoid any interference with the heating surface (Fig. 3). At the end of the last period of galloping, the horse was stopped, and the step was avoided because it would complicate the data evaluation. At the end of trial, the horse was subjected to the application of cold water at $6^{\circ} \mathrm{C}$ that was washed from the neck to the back three times over a period of 10 seconds and was repeated six times every 30 seconds; then the horse received a total of 6 cycles each of 30 seconds of water and 30 seconds of rest. The surface temperature of the horse before exercise had a mean of $33.5^{\circ} \mathrm{C}$. After the first cooling cycle, the part irrigated by water at $6^{\circ} \mathrm{C}$ showed 


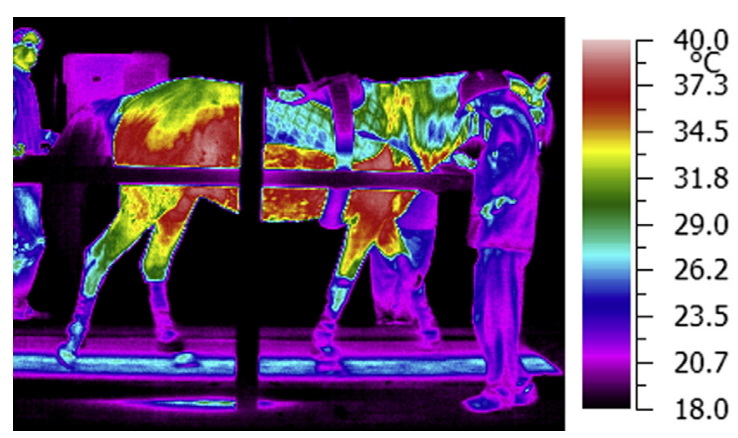

Fig. 3. Thermographic image of a horse during a treadmill session.

an average temperature of $19.2^{\circ} \mathrm{C}$, whereas the region of the inner thigh that had not been reached by the flow of water had a higher temperature. At 25 seconds after the first cycle, the temperature returned to an average of $35^{\circ} \mathrm{C}$. At the end of the last application of water, the average was $19.2^{\circ} \mathrm{C}$, but within 30 seconds after the water application, a temperature of $22^{\circ} \mathrm{C}$ was registered. At $5 \mathrm{~min}$ after the sixth cycle of cooling, the average temperature was $34^{\circ} \mathrm{C}$, so only $0.5^{\circ} \mathrm{C}$ above the initial value. It is necessary to underline the rapid increase in temperature after the first cycle, which indicates that the application of water at $6^{\circ} \mathrm{C}$ did not compromise the blood flow surface, whereas the data collected after the fifth and sixth cycle show that the low median water temperature produced a phenomenon of peripheral vasoconstriction. With the help of thermography, the study demonstrated that even after a cooling protocol with the application of cold water $\left(6^{\circ} \mathrm{C}\right)$, three times at 30 seconds interval, the body surface temperature returns to the same level as it was before the trail (Fig. 3).

\section{Thermoregulation of Weaned Horses}

A study in 2007 [20] assessed the ability of thermography to monitor the temperature in the weaning of nine horses kept outdoors in winter in the Nordic countries (Kiuruvesi, Finland). The experiment was carried out between December 2003 and February 2004, thermographic scans were made in different environmental conditions: outdoor temperature ranged between $0^{\circ} \mathrm{C}$ and $-23^{\circ} \mathrm{C}$, the thermographs were always taken at $10 \mathrm{AM}$, and images were taken from a lateral view and from a distance of 8 meters.

The heat loss by irradiation from the neck and trunk does not change when the environmental conditions range between $0^{\circ} \mathrm{C}$ and $-9^{\circ} \mathrm{C}$, but it increases if the temperature drops to $-16^{\circ} \mathrm{C}$. The body loses less heat to $-23^{\circ} \mathrm{C}$ than to a temperature of $-16^{\circ} \mathrm{C}$, whereas the neck showed no differences between these two conditions. The heat loss at $-23^{\circ} \mathrm{C}$ was greater than the heat loss at $0^{\circ} \mathrm{C}$ but similar to that observed at $-9^{\circ} \mathrm{C}$.

The higher heat loss was recorded with an outdoor (environmental) temperature of $-16^{\circ} \mathrm{C}$. This may mean that the lower limit temperature of horses during weaning is between $-9^{\circ} \mathrm{C}$ and $-16^{\circ} \mathrm{C}$. The figure which expresses a lower heat dissipation at $-23^{\circ} \mathrm{C}$ must be interpreted taking into account that the scan has detected a thin layer of rime ice on the body surface of the subjects, is therefore likely that this has reduced the surface temperature.

This study has shown that thermography is an excellent method to evaluate the welfare conditions of horses kept outdoors, in the paddocks.

\section{Discussion and conclusions}

In recent years, infrared thermography has proven particularly useful both in the diagnostic field and in physiological assessments, highlighting its characteristic noninvasive technique. By many process applications in this paper, thermography has increasingly gained an important position in equine medicine and management.

Regarding the physiological assessments, thermography has proven to be very useful in detecting temperature variations of specific body parts of the horse in certain physical and environmental conditions. The results obtained from these studies can be used for the management of the sporting horse: from exercise under specific environmental conditions to the necessary care following a training session. Furthermore, it has been shown that as growing horses have a different thermoregulatory control than adults, this result should be taken into account in the management of the weaning period. As already mentioned, within the techniques of diagnostic imaging, thermography in particular has the advantage of being the least invasive. The ability of thermography to detect the development of inflammation has been demonstrated by several studies; specifically, we have seen how this technique is able to point out the onset of inflammation, especially when related to the musculoskeletal apparatus, earlier than clinical examination and other imaging techniques. Another area in which this technique can be helpful is neurology, where several research protocols are under study to understand how thermography can be optimized for the evaluation of neurological conditions.

In addition, the thermographic method was effective in more specific applications such as searching for prohibited substances and during equestrian competitions, or for the early diagnosis of casting lesions and summer dermatitis. Thermography is also useful in the pharmaceutical field as a means of assessing the vasomotor effects caused by the use of specific substances such as corticosteroids.

Thanks to its versatility, lack of invasiveness, and high sensitivity, thermography has countless applications; however, paradoxically, the major limit to the technique in the veterinary field is its ease of use. In fact, a thermal image of an animal in motion often shows abnormalities that are not directly related to a physical problem or dependent on various external causes, including environmental and measurement conditions. It should also be remembered that in biology, differences between subjects due to individual variability are not negligible.

One of the aims of this work was to provide an overview of the possible applications of thermography in equines. We believe that the perspectives for quantitative application are opened in the direction of the examples and not only in research centers but in general veterinary and management practice. 


\section{References}

[1] Rosenmeier JG, Strathe AB, Andersen PH. Evaluation of coronary band temperatures in healthy horses. Am J Vet Res 2012;73(5): 719-23.

[2] Kastberger G, Stachi R. Infrared imaging technology and biological applications. Behav Res Methods Instrum Comput 2003;35(3): 429-39.

[3] Okumus Z, Yanmaz LE. Instrumentation of thermography and its applications in horses. J Anim Vet Adv 2007;6:858-62.

[4] Chiminelli E. - Università degli Studi di Milano. Facoltà di Medicina Veterinaria - Corso di Laurea in Medicina Veterinaria - Utilizzo della tecnica termografica in ippiatria. Relatore: Fabio Luzi -Correlatore: Francesco Ferrucci e Veronica Redaelli. Aa. 2008-2009.

[5] Kraft SL, Roberts GD. Modern diagnostic imaging. Vet Clin North Am Equine Pract 2001;17(1):93-113.

[6] Turner TA. Thermography as an aid to the clinical lameness evaluation. Vet Clin North Am Equine Pract 1991;7:311-38.

[7] Eddy AL, van Hoogmoed LM, Snyder JR. The role of thermography in the management of equine lameness. Vet J 2001;162:172-81.

[8] Becker-Birck M. Cortisol release, heart rate and heart rate variability, and superficial body temperature, in horses lunged either with hyperflexion of the neck or with an extended head and neck position. J Anim Physiol Anim Nutr 2012.

[9] McGreevy P. The effect of double bridles and jaw-clamping crank nosebands on temperature of eyes and facial skin of horses. J Vet Behav 2012;7:142-8.

[10] Arruda TZ. Thermographic assessment of saddles used on jumping horses. J Equine Vet Sci 2011;31:625-9.

[11] Fleischmann T. Thermal imaging as an aid to the diagnosis of pain in horses - first results. World Congress on Medical Physics and
Biomedical Engineering, September 7-12, 2009, Munich, Germany. IFMBE Proceedings 25/2, 2009. p. 277-280.

[12] Ludwig N, Gargano M, Luzi F, Carenzi C, Verga M. Technical note: applicability of infrared thermography as a noninvasive measurements of stress in rabbit. World Rabbit Sci 2007;15: 199-205.

[13] Valera M, Bartolomé E, Sánchez MJ, Molina A, Cook NJ, Schaefer AL. Changes in eye temperature and stress assessment in horses during show jumping competitions. J Equine Vet Sci 2012;32:827-30.

[14] Erber R. Physiological and behavioural responses of young horses to hot iron branding and microchip implantation. Vet J 2012;191: 171-5.

[15] Levet T. Distal limb cast sores in horses: risk factors and early detection using thermography. Equine Vet J 2009;41:18-23.

[16] Epp T, Gaughan EM, Simon EL, Spire M. Influence of exercise on thermographically determined surface temperatures of thoracic and pelvic limbs in horses. J Am Vet Med Assoc 2006;229:1940-4.

[17] Henson FMD, Tunleyb BV. Reliability and repeatability of thermographic examination and the normal thermographic image of the thoracolumbar region in the horses. Equine Vet J 2004;36: 306-12.

[18] Geor RJ, McCutcheon LJ. Thermoregulatory adaptations associated with training and heat acclimation. Vet Clin North Am Equine Pract 1998;14:97-120.

[19] Casas I, Holah G, Marlin DJ, Roberts CA, Schroter RC, Scott CM. Post exercise changes in compartmental body temperature accompanying intermittent cold water cooling in the hyperthermic horse. Equine Vet J 1998;30:28-34.

[20] Autio E, Heiskanen ML, Mononen J. Thermographic evaluation of the lower critical temperature in weanling horses. J Appl Anim Welf Sci 2007;10:207-16. 